\title{
CRÍTICA DE LA RAZÓN PRECARIA. LA VIDA INTELECTUAL ANTE LA OBLIGACIÓN DE LO EXTRAORDINARIO
}

\author{
Critique of Precarious Reason. Intellectual Life in the face of the Obligation of \\ the Extraordinary
}

Albert Jornet-Somoza

University of Pennsylvania

albert.jornetsomoza@gmail.com

Reseña de: LÓPEZ ALÓS, Javier (2019). Crítica de la razón precaria. La vida intelectual ante la obligación de lo extraordinario. Madrid: Catarata, pp. 140.

Vivimos tiempos precarios que cada vez son más percibidos como tal. La precariedad del presente lleva hoy más de una década situada como uno de los problemas más urgentes de los debates políticos, antropológicos y filosóficos, no sólo en España sino a escala global. Aportaciones como las de Judith Butler, Guy Standing e Isabell Lorey — fuera del estado español- o Marina Garcés, Jorge Moruno y Remedios Zafra - dentro- han sido, entre muchos otros y a pesar de sus diferencias, cruciales para ir demarcando sus contornos hasta llegar a una suerte de lenguaje común que nos permite entenderlo como un fenómeno agudizado por esa nueva razón del mundo que, según Laval y Dardot, se ha ido hegemonizando a escala planetaria en las últimas décadas: el neoliberalismo. Una precariedad que no sólo tiene que ver con las formas de carestía generalizadas en un orden mundial cada vez más desigualitario ni con los mecanismos de desaparición del antiguo paradigma del empleo en lo que algunos pensadores Ilaman "post-trabajo", sino que, por encima de todo, actúa como un eficaz instrumento biopolítico de gubernamentalidad que determina y disciplina las prácticas, las relaciones y las condiciones de vida de los individuos.

La aportación de Javier López Alós con Crítica de la razón precaria supone un repliegue reflexivo del pensamiento por cuanto se propone indagar sobre las transformaciones y consecuencias que el marco precarizador está conllevando para el propio pensamiento, es decir, analizar "las formas en las que la precariedad incide en el ejercicio de la razón y afecta a la actividad del pensamiento orientado al juicio público" (17) como condición de formulación de la pregunta que sobrevuela y vertebra todo el libro: "cómo vivir, cómo ser libres, cómo pensar, crear y entrar en conversación franca con los otros a pesar del miedo" (19). El propio gesto supone ya una toma de posición y un desplazamiento respecto a la tradición intelectual, pues reivindica la necesidad de situar la tarea reflexiva y de considerar las condiciones materiales de la toma de palabra. Quizás por ello, el ensayista alicantino arranca su 
obra explicitando su lugar de enunciación; una obra marcada por su condición de "emigrado como tantos, y que sólo últimamente, cumplidos los cuarenta, ya en España y en paro, he podido redactar como es debido" (13). Una triple subalternidad, pues, moldea su escritura, en la cual, además del desplazamiento geográfico y el desempleo, no es menos significativa la alusión a la edad, por cuanto se presenta como la voz colectiva de la primera generación española en democracia "cuya mayoría de miembros no hemos tenido experiencia de estabilidad laboral" (32).

De esta nota confesional, sin embargo, no se infiere que la tarea del ensayista sea sólo la de dar cuenta de su situación sino más bien que debe ser asumida en la propia labor crítica, para lo cual reclama el papel de la experiencia:

\begin{abstract}
Hablar de experiencia - dice López Alós- implica la capacidad de extraer conocimiento de lo vivido. No es mera vivencia ni cúmulo desordenado de sensaciones que alguien rememora. Por el contrario, implica una operación reflexiva que exige distancia emocional respecto al fenómeno, como si no consistiera en algo que enraíza al sujeto. [...] Esta no supone imparcialidad (¿cómo ser imparcial? ¿cómo y por qué fingir que uno no está interesado personalmente en aquello que personalmente le afecta?) ni falta de pasión. (24).
\end{abstract}

Estamos pues ante una obra de intervención que aspira a hacer trinchera desde la dilucidación y denuncia de los cambios que amenazan con menoscabar las condiciones de posibilidad del pensamiento crítico, es decir, bajo la expansión colonizadora del neoliberalismo, de la cual los espacios e instituciones de producción de sentido no pueden resultar ajenos. Por eso, uno de los principales focos de atención de la obra es el papel de la universidad en la transformación del trabajo académico, que, con menor o mayor intensidad según el país, lleva décadas plegándose al dictado productivista, impulsando la competitividad como principio motor de la investigación o adoptando medidas de cuantificación del saber para alimentar rankings, impactos y evaluaciones de toda índole, mientras que las condiciones laborales no cesan de sufrir constantes medidas de precarización bajo el signo de la temporalidad, la bajada de salarios, la burocratización o la imposición de objetivos casi inalcanzables, que han contribuido a crear ese "gran ejército académico de reserva" (40) que conforman hoy los profesores asociados, los becarios, los investigadores adjuntos y tantas otras figuras contractuales vulnerables. López Alós conoce bien la situación por su propia trayectoria profesional y por eso mismo intenta concienzudamente que su propia escritura se sitúe en un afuera respecto a la institución universitaria y sus efectos domesticadores para el pensamiento. De ello da buena cuenta el uso de un lenguaje que evita tanto los tecnicismos hipercodificados como esa supuesta impersonalidad estandarizada por el formato anglosajón del paper, con el objetivo de salirse del juego académico de reconocimientos, legitimación y distinción simbólica. Por el contrario, su estilo sobrio y personal, aunque no exento de hondura conceptual, arranca de la premisa de estirpe kantiana — seguramente lo que lo acerca más al filósofo prusiano, además del evidente eco en el título- de que "la única esperanza para la inteligencia de las cosas es distinguirlas bien" (19) aun si eso no supone huir del recurso retórico 
puntual, especialmente en la producción de imágenes y símbolos que ayudan a plasmar simbólicamente, con figuras clarividentes, los fenómenos que describe.

A partir de esta voluntad, la obra puede leerse como un retrato robot del precariado intelectual a través del análisis de los dispositivos que encuadran el trabajo cultural y de las consecuencias afectivas y psicológicas para aquellos que pretenden sostener sus vidas poniendo su mente y su creatividad al trabajo. Uno de estos dispositivos es, sin duda, el de la imposición de la competitividad: una competitividad que cuando se establece como "principio rector de la vida intelectual y de la producción cultural produce efectos de barbarización" (62) pues instala un paradigma regulador de conductas en el que imperan el sálvese quien pueda y el cortoplacismo en cualquier posición y a cualquier escala. Por eso mismo debemos considerar, a su vez, la precariedad no sólo como la ocupación de una posición de carestía social más o menos eventual o más o menos duradera, sino una forma de subjetividad que acaba atañendo a todos los peldaños y ocupaciones del abanico laboral:

muchos de los males y problemas que identificamos en la precariedad son transversales a diversas escalas de salario y tipos de contrato, que no es solo un asunto económico, sino el reflejo de una forma de entender la vida profundamente destructiva para todos. Incluso para los que obtienen mayor remuneración y reconocimiento. Aunque no todos seamos igual de vulnerables, lo cierto es que esta competencia salvaje pone a todo el mundo en peligro. Y vivir obligado a participar de la lucha, o temeroso de verse en ella y perder lo que se ha conseguido, siempre alerta, tiene consecuencias para la mayoría de las personas. (63)

Este principio barbarizador de la competitividad está en la base del precariado intelectual, que agota su tiempo de vida porque lo pone todo al trabajo y que acaba figurándose como sujeto en deuda, pues termina habitando en un tiempo de postergación o aplazamiento constante, ya que sólo en el futuro es capaz de situar tanto sus deseos en forma de proyectos como el cumplimiento de todos los deberes y tareas acumuladas -laborales o extraprofesionales- que el presente asfixiado no le permite. A esto es a lo que López Alós Ilama la "obligación de lo extraordinario", pues el precario está siempre obligado a esperar lo excepcional que le permita alzarse por encima de sus competidores en la búsqueda de unas condiciones de vida estables y dignas. De ahí que algunas de las lógicas consecuencias, señaladas por el ensayista, sean no sólo la frustración, el bloqueo o la desmoralización ante la postergación indefinida de su obtención - o ante la insatisfacción de los resultados obtenidos- sino en última instancia la generalización de la ansiedad, las enfermedades mentales o las adicciones, que han incrementado exponencialmente en los últimos años. $Y$ todo ello en unos entornos laborales que obligan a los competidores a exhibir constantemente una renovada y ostentosa pasión por su trabajo y en los que, consiguientemente, resulta imposible mostrarse vulnerable, pues ello pone en ventaja a los demás competidores.

En definitiva, López Alós desgrana uno por uno los motivos que inducen a pensar que hoy en día el trabajo académico y cultural no sólo se ha convertido en punta de 
lanza de la destrucción neoliberal del paradigma del trabajo sino que, tal como se configuran hoy las instituciones universitarias, en cierta medida se están erigiendo, por paradójico que pueda parecer, como obstáculos para el pensamiento crítico. Por eso, uno de los grandes valores de la obra es el de poner el dedo en la llaga de estos dispositivos precarizadores como condición previa para poder repensar el papel de la imaginación política y de la función intelectual como motores de transformación y emancipación. Ante todo, nos dice repetidamente, urge encontrar dinámicas de cooperación que puedan contraponerse a las de la competitividad omnipresente, es decir, plantearnos "si podemos construir formas de reconocimiento más cooperativas, proporcionadas y justas que las que ahora palidecen y algunas de las que pugnan por sustituirlas" (38). Y ello pasa, en primer lugar, por abandonar el imperativo productivista que pone el conocimiento a merced de la lógica mercantil, para impugnar la paradoja de lo posible que establece el marco neoliberal, a saber, aquella que refuerza una concepción del deseo individual tendente a infinito mientras que asevera que el margen de acción colectiva o social tiende inexorablemente a cero. Por eso,

la batalla cultural debe asumir el reto contrario: por una parte, reducir las expectativas sobre el cumplimiento de nuestros deseos y tomar mayor conciencia de nuestros límites como individuos; por otra, combatir la falacia naturalista que nos induce a confundir realidad y necesidad como si no hubiera más posibilidades que lo que hay (y aceptarlo fuera nota de sensatez política) (113).

Para ello, el ensayista termina proponiendo la figura del intelectual plebeyo, contrapuesto al del precario intelectual, como aquél que asume sus propios límites y su condición vulnerable y precaria a la vez que no renuncia a la vida buena y al compromiso con la vida intelectual, para lo cual reivindica la necesidad de la crítica a las fuentes de la injusticia social.

Con este ensayo, digno merecedor del premio Catarata, Javier López Alós agranda esa lista generacional de ensayistas españoles indispensables para entender el presente que conforman voces cercanas a la suya como Marina Garcés, César Rendueles, Remedios Zafra, Alberto Santamaría o Jorge Moruno. Pero hay mucho más que eso: también resulta un lúcido espejo donde cualquiera de los que nos encontramos o que hemos pasado por las filas de la academia nos vemos reflejados en una crudeza deslumbrante que huye por igual del cinismo y del cruel optimismo. Libros como este deben contribuir a que nos tomemos muy en serio nuestra complicidad - la de todos los que nos dedicamos a esto del pensar y el escribircon el deterioro de las formas de vida digna y de la justicia social que avanza imparable al son del credo neoliberal. Como advierte López Alós, resulta indispensable que dejemos de reproducir las imágenes de éxito que saturan nuestro ideario, que recuperemos la escala de lo real, que alimentemos entre todos la potencia de la crítica y de la imaginación política al servicio de la igualdad y la justicia social y que generemos entornos para el pensamiento en los que primen la cooperación y los cuidados, o sea, haciéndonos cargo de la vulnerabilidad y el sostenimiento de la vida. Tarea que, como afirma la última palabra del ensayo, solo podemos llevar a cabo JUNTOS.

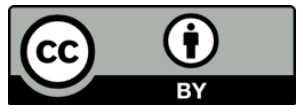

